\title{
As margens plácidas de O quinto dos infernos
}

Renato Luiz Pucci JR. Universidade Tuiuti do Paraná / UTP 


\section{Resumo}

A minissérie $O$ Quinto dos Infernos é comparada com o filme Carlota Joaquina, Princesa do Brazil, de modo a se destacar, nos termos de Linda Hutcheon, alguns traços pós-modernistas e a precariedade de sua metaficção historiográfica.

\section{Palavras-chave}

cinema, televisão, narrativa, historiografia, pós-modernismo

\section{Abstract}

The serial $O$ Quinto dos Infernos is compared with the film Carlota Joaquina, Princesa do Brazil, in order to point out, in Linda Hutcheon's sense, some postmodernist traces and its unaccomplished historiographic metafiction.

\section{Key words}

cinema, television, narrative, historiography, postmodernism 
$1 \begin{aligned} & \text { exibição da minissérie } O \text { Quinto dos Infernos pela Rede } \\ & \text { Globo, escrita por Carlos Lombardi e dirigida por Wolf Maya } \\ & \text { e Alexandre Avancini (2002), enseja a reavaliação de }\end{aligned}$ aspectos da representação da história e dos grupos sociais nos meios de comunicação contemporâneos. O interesse específico provém de ser a minissérie um retorno a um período histórico e a personagens já retratados em outras ocasiões, principalmente nos longas-metragens Independência ou Morte (Carlos Coimbra, 1972), o épico ufanista lançado em plena ditadura militar, e Carlota Joaquina, Princesa do Brazil (Carla Camurati, 1995). Elementos comuns às três produções, como a presença da personagem Carlota Joaquina, fazem com que fiquem mais claras as diferenças devidas a circunstâncias das respectivas épocas de exibição e também aos meios em que foram veiculadas.

Cercadas por intensa polêmica, pois cada uma das três realizações desagradou parcela substancial de críticos e historiadores', foram por mim abordadas em outras ocasiões com a finalidade de destrinchar questões estilísticas e historiográficas. No presente trabalho, resultado dos primeiros passos de pesquisa acerca da interface entre cinema e TV pós-modernos, o foco incide primordialmente sobre a minissérie e, em especial, na sua representação de minorias sociais. Para tanto, serão retomados alguns aspectos desenvolvidos nos outros textos, aos quais remeterei os leitores que queiram mais esclarecimentos.

É inegável a relação intertextual direta de Carlota Joaquina, Princesa do Brazil com $O$ Quinto dos Infernos. É dela um forte indício a indignação quase em idênticos termos tanto de historiadores

1. V., por exemplo, Bernardet (1978), Vainfas (2001) e Mello (2002). 
como de membros da família real portuguesa, conforme amplamente noticiado na imprensa (Pucci Jr., 2003b). É desnecessário voltar ao assunto. $\mathrm{O}$ que ainda necessita melhor exame são as diferenças entre as duas produções. No nível dos roteiros, é evidente que a minissérie não possui a intensa compactação do filme, ao se desdobrar, em múltiplas linhas narrativas paralelas, à maneira folhetinesca consagrada na TV. Enquanto o filme se voltava decisivamente para a figura de Carlota Joaquina, na minissérie abrem-se histórias paralelas que, às vezes, confluem e se cruzam. É assim que, ainda na parte que se passa em Portugal, surgem Gomes (interpretado por Humberto Martins) e Manuela (Danielle Winits), cujas aventuras se desenvolvem à maneira da tradição picaresca, como em Tom Jones, de Henry Fielding. Está claro que a própria condição de realização televisual, com investimento pesado que precisa ser recuperado ao longo dos capítulos, fez com que se tornasse imperiosa a descentralização narrativa, até o ponto de se encontrarem subplots praticamente dispensáveis, como o da Condessa Branca (Bruna Lombardi), que de súbito faz as vezes de "ladrão de casaca" e é assediada por Gomes, personagens inexistentes no longa de Carla Camurati.

Na minissérie, a relevância de Carlota Joaquina (Betty Lago) é suplantada não apenas por Gomes mas, principalmente, por D. Pedro (Marcos Pasquim). A partir de certo ponto, não muito longe do início, a história se desvia para o futuro imperador do Brasil, deixando Carlota um tanto ofuscada, exceto nos esparsos momentos em que surge com um ar ainda mais malévolo e encantatório do que sua correspondente dos anos noventa, interpretada por Marieta Severo. A aludida dispersão narrativa é compensada pela copiosidade dos quarenta e oito capítulos, que permitem um desenvolvimento impossível num longa-metragem. D. Pedro é a figura de maior destaque, detendo-se a narração em suas inúmeras peripécias amorosas e dionisíacas, o que se distingue drasticamente da configuração apagada do personagem em Carlota Joaquina (interpretado por Marcos Palmeira): em troca das poucas cenas em que então aparecia, seja no âmbito privado ou público, na minissérie abundam situações em que o futuro imperador revela um caráter pantagruelesco 
que interfere no desenrolar de ocasiões históricas. A independência, exemplificando, é declarada após um lauto almoço em companhia de José Bonifácio (Paulo Goulart), de que resulta a imperiosa diarréia de $\mathrm{D}$. Pedro no momento crucial do nascimento da nação. O relacionamento extraconjugal com Domitila (Luana Piovani) e o casamento com Amélia (Cláudia Abreu) recebem longas seqüências, naturalmente picotadas na edição de modo a se entrecruzar com as histórias paralelas.

$\mathrm{O}$ aspecto convencional da minissérie se contrapõe à discreta sofisticação da narrativa de Carla Camurati, que conta com um brilhante artifício de distanciamento: a narração através dos escoceses. Emoldurando a história de Carlota e pontuando-a através de intrusões narrativas, estão Yolanda e o rapaz que lhe conta a história da princesa do Brasil. Tem sido estudado o papel desses personagens na articulação do filme (Gatti, 2000; Nascimento, 2001), ficando claro que não se trata de um recurso banal como se pode ter julgado a princípio. Cenas como aquela em que a voz extradiegética de Yolanda comenta a quantidade de bebês de Carlota, como se a menina escocesa assistisse ao mesmo filme a que assiste o espectador, induzem a produção da inverossimilhança generalizada no nível da estrutura narrativa, elemento inexistente na minissérie. Pretendo, com isso, indicar que na transposição para a TV a história de Carlota Joaquina ganhou na profusão de detalhes dos personagens e das situações experimentadas, mas também perdeu em refinamento narrativo.

O tópico mais característico dessa heterogeneidade está no tratamento do que a teórica canadense Linda Hutcheon denominou metaficção historiográfica. Tendência típica da literatura pós-moderna, é identificável já nos anos sessenta em romances como A Mulher do Tenente Francês, de John Fowles. Trata-se da forma ficcional que incorpora o núcleo do repensar pós-moderno sobre os problemas relativos à maneira como podemos e conseguimos ter conhecimento a respeito do passado (Hutcheon, 1991, p. 126). Em consonância com o Novo Historicismo, a metaficção historiográfica propugna que a narrativa ficcional e a histórica, tidas como inconfundíveis desde o século XIX, seriam intrinsecamente ligadas, pois o discurso histórico se baseia na narrativa, como sempre o fez a ficção 
(White, 1994, p. $25-27$ e 1998, p. 192-200). A metaficção historiográfica nada mais faria do que exibir esse vínculo, misturando os elementos em jogo, inserindo o contexto histórico na ficção para, em seguida, questionar o discurso proposto. Há, portanto, a combinação autoconsciente entre o histórico e o fictício, como em $O$ Nome da Rosa, de Umberto Eco, em que dados históricos da Idade Média convivem com a paródia a Sherlock Holmes. Na mesma linha está Midnight Children's/Os Filhos da Meia-Noite, de Salman Rushdie, cujo protagonista nasce no dia em que Índia e Paquistão se separam e formam Estados independentes, unindo-se a história do garoto à dos dois países, de modo que ele se torna o causador de fatos históricos do mais amplo alcance, como o conflito armado indopaquistanês de 1965. Ressalte-se que, diferentemente dos romances históricos tradicionais, os dados históricos não são utilizados com o fim de incrementar a verossimilhança, solapada desde a base em função da extravagante mistura entre ficção e eventos históricos.

Até onde se pode constatar, a metaficção historiográfica chegou tardiamente ao cinema, no início dos anos oitenta, $\operatorname{com} A$ Mulher do Tenente Francês (Karel Reisz, 1981), adaptação da citada obra de John Fowles, com imaginativas soluções para a transposição do pós-modernismo para a tela. Possivelmente o primeiro filme nacional a se compor de acordo com esses princípios tenha sido Carlota Joaquina, cujo paradigma de construção é o mesmo dos mencionados romances pós-modernos, ou seja, põe-se em questão o modelo realista da representação, sem que este seja de antemão destruído (como sempre o fez a literatura e o cinema modernistas). A metaficção instaura o conhecido, ou seja, uma certa tradição narrativa de amplo alcance (no caso, a cultura popular de massa) e a subverte através da paródia lúdica (Hutcheon, 1989, p. 105, 119). É assim que em Carlota Joaquina são utilizados elementos do filme histórico clássico, por exemplo de Independência ou Morte, instaurando-se a comunicação com o grande público, mas de forma que regularmente se subvertem as normas de verossimilhança através da paródia lúdica daquele épico. A utilização dos narradores escoceses atua nesse sentido. Em princípio o recurso nada mais seria do que una forma narrativa tradicional, visto que, há muito tempo, 
existem filmes em que, a partir da narração de personagens, inicia-se um grande flashback em que se acompanha o que é narrado: Como era Verde o meu Vale (John Ford, 1941), A Condessa Descalça (Joseph L. Mankiewicz, 1954) e, mais recentemente, Titanic (James Cameron, 1997) etc. Em Carlota Joaquina, porém, as mencionadas intrusões de Yolanda na diegese são alguns dos elementos a subverter a credibilidade da narração. $O$ processo atinge o ponto máximo ao final, quando volta-se aos escoceses, e Yolanda pergunta se é verdade que Carlota Joaquina envenenou D. João VI. Eis a resposta:

Escocês: Quem sabe, Yolanda? O problema com a Historia é que quanto mais se lê, menos se sabe. Cada um tem uma versão diferente para o mesmo fato. "Quem sabe?" - essa é a sua resposta.

O que o rapaz acabou de narrar é uma versão, não a verdade histórica. Não se procurou autenticar o discurso através dos tradicionais recursos de filmes baseados na historiografia tradicional. A mistura inextricável entre o relato histórico do escocês e a imaginação de Yolanda pode produzir não a resoluta credibilidade nos fatos narrados, mas a sua problematização. ${ }^{2}$

Um pouco disso existe em $O$ Quinto dos Infernos, a começar da paródia lúdica, tanto ao romance picaresco como ao filme histórico, de aventuras e, no final, ao melodrama. Além do mais, tal como em Carlota Joaquina, personagens e situações históricas são conotadas com flagrantes anacronismos que denunciam a ausência de pretensão de se criar um discurso histórico fiel. Entre as incontáveis ocorrências do tipo, podem-se mencionar apenas a título de ilustração:

1. O aparelho de musculação em que malha D. Pedro, feito com madeira e pedras, porém em tudo o mais semelhante ao que se encontram em academias dos dias de hoje;

2. Para mais detalhes acerca da diferença entre a historiografia tradicional e o Novo Historicismo, respectivamente incorporados por Independencia ou Morte e Carlota Joaquina, v. Pucci Jr., 2000. 
2. A insistente audição de composições musicais ainda não existentes na época em que se passa a história, como a "Habanera", da ópera Carmen, de Bizet (que é de 1875), Leitmotiv de Carlota Joaquina; ou "My Heart Belongs to Daddy", de Cole Porter;

3. Referências diversas a filmes célebres, como em "Aquele monstro da lagoa negra!", esbravejar de Domitila contra um desafeto, ou o pedido de $\mathrm{D}$. Pedro para que o irmão Miguel (Caco Ciocler) lhe arrume um pouco de manteiga para servir de ingrediente em relações sexuais, alusão certa a OÚltimo Tango em Paris (Bernardo Bertolucci, 1972).

A exuberância intertextual, sempre a esvanecer a verossimilhança, está também na carruagem descontrolada que, com Domitila dentro, cai de um despenhadeiro e mergulha no mar apenas para que D. Pedro salve a amada; na virgem Manuela, que chorando acaba no bordel; no assobio de Pedro para chamar seu cavalo, que o atende prontamente; na chegada de Pedro ao porto para receber Amélia, galopando intrépido como o heróico cavaleiro com que sonhava a princesa. Tudo isso é reminiscência de filmes de aventuras ou melodramas de outras épocas. Poderia ser apenas uma utilização de esquemas arcaicos, não fosse o caráter lúdico que permeia cada referência, como ocorre em virtude do desmaio de D. Pedro justamente quando desce do cavalo e se dirige à futura esposa. Operase, por conseqüência, com o que é familiar ao público para logo em seguida introduzir um elemento destoante, que rompe o traçado da narração convencional. É justamente a essa combinação paradoxal entre elementos da cultura de massa e de recursos de distanciamento (cuja procedência modernista é inegável) que Linda Hutcheon chamou de pós-modernismo, seguindo uma tendência que teve outro defensor em Andreas Huyssen (1986). Este propôs a idéia de que o pós-modernismo se caracterizaria pela superação do que denominou "Great Divide", isto é, a defesa intransigente da separação radical entre alta cultura e cultura de massa, tal como proposta pelos modernistas em geral. Há longinquamente algo da transposição dessa fronteira em $O$ Quinto dos Inferno, entretanto nada 
que se equipare ao que ocorre em Carlota Joaquina. ${ }^{3}$ Nenhum dos elementos mais sofisticados desta última produção são encontrados na minissérie, em que a narração se processa à maneira convencional, sem as intrusões abruptas e antinaturalistas de personagens narradores. Um dos pontos curiosos está em que, apesar de tanta liberdade para com a história oficial, a definição dos fatos históricos se processa sem a ambigüidade do filme de Carla Camurati. Um exemplo está na definição de que, sim, Carlota envenenou D. João VI, o que realça ainda mais a péssima índole da personagem na minissérie, deixando-a mais próxima das bruxas de desenhos de Walt Disney, traço visualmente sugerido por suas súbitas aparições, com o cabelo armado, chapéus imensos e expressão arrogante e má. Existe a mistura entre fatos históricos e ficção, contudo não à maneira do filme.

Toda a ênfase da minissérie está não em refinados aspectos de narração, mas em elementos mais próximos da cultura popular de massa. Em outras palavras, a balança do paradoxo pós-moderno não se equilibra nem pende para a herança modernista. Ressalte-se a proliferação do grotesco, que, apesar de toda a divulgação da concepção bakhtiniana, ainda hoje fere olhos e ouvidos da elite cultural. De fato, por todo lado encontram-se referências ao "baixo corporal", bem mais do que em Carlota Joaquina:

1. D. Pedro acometido por vômito e dor de barriga ainda tem forças para uma ereção em vista de mulher alheia;

2. A imperatriz Leopoldina cai em cima de D. Pedro, solta gases e, sem querer, acerta o joelho na genitália do marido;

3. Leopoldina vomita em D. Pedro, prenúncio da gravidez;

4. A barriga de D. Pedro a roncar quando há fome;

5. A ejaculação precoce por Amélia;

6. Comilança e bebedeira desenfreadas de D. Pedro, que invariavelmente termina a madrugada nu, no chafariz público, completamente embriagado;

3. Desenvolvi o exame do pós-modernismo de Carlota Joaquina em Pucci Jr., 2003a, p. 234-250. 
7. O caráter sexualmente incontrolável de D. Pedro, sempre a perseguir mulheres seja no dormitório real, nas estrebarias do palácio ou em qualquer outro lugar;

8. O tiro nas nádegas da irmã de Domitila, Benedita, que havia narcotizado D. Pedro para dormir com ele;

9. A diarréia que acomete $\mathrm{D}$. Pedro durante o sacrossanto momento da proclamação da Independência.

Tudo isso indica a conexão com a cultura popular de massa. A inserção, ao final do último capítulo, de imagens de carnaval, com os atores a desfilar na avenida com as indumentárias de seus respectivos personagens, é uma prova circunstancial de que a proposta que dirige a minissérie tem inspiração bakhtiniana. Evidentemente não se trata de uma ligação direta com a cultura popular, de que hoje em dia há apenas reminiscências do descrito e analisado por Bakhtin. A fonte primordial para essa constituição está nas formas mais populares do cinema brasileiro em termos de comédia: a chanchada e a pornochanchada, cujo rigoroso vínculo com Carlota Joaquina e $O$ Quinto dos Infernos analisei em outro texto (Pucci Jr., 2003b). Aqui cabe dar alguns passos adiante nas conclusões e analisar as consequiências dessa relação em vista das representações sociais veiculadas na minissérie.

Definindo-se a chanchada como um subgênero da comédia cinematográfica, com raízes na cultura popular, isto é, no humor outrora praticado em circos e teatros de revista, passando por populares programas radiofônicos, é inegável a associação com a minissérie: nesta existe a herança daquele humor fácil, escrachado, quase sempre físico, sem erudição ou mesmo zombando de eruditos e esnobes, e, acima de tudo, capaz de facilmente se comunicar com o grande público. A multiplicação de cenas com Domitila enraivecida contra D. Pedro, atirando-lhe vasos e impropérios por questões de infidelidade, traz à tona personagens de Zé Trindade e Oscarito, entre outros, a sofrer o diabo nas mãos das respectivas esposas em função de saltos ou tentativas de saltos da cerca conjugal.

A relação com a pornochanchada é ainda mais clara, haja vista a proliferação de palavrões e de situações eróticas 
que propiciam o humor fácil e com frequiência grosseiro. A título de exemplo, mencione-se o assédio feminino a D. Pedro após o falecimento da imperatriz, quando o personagem se entrega a consecutivas relações sexuais com mulheres que não pensam em outra coisa. Tudo isso é examinado no mencionado texto em que comento a relação de $O$ Quinto dos Infernos com chanchada e pornochanchada.

Um ponto então abordado de passagem foi o da transformação do pênis de $\mathrm{D}$. Pedro em personagem, de quem se fala seguidamente e que parece possuir um comportamento próprio, à revelia de seu dono. "Presentinho é modéstia vossa", "varinha mágica", "porta-jóias real", "sua arma", "Tu ficas quieto" (e joga-lhe água fria para acalmá-lo) são apenas algumas da incontáveis formas tergiversantes de se fazer referência ao órgão sexual do protagonista. Sem dúvida, há também nisso relação com a pornochanchada, em que o nunca exibido órgão sexual masculino recebia tratamento semelhante. Digno de nota é o caráter falocêntrico da narração. Evidentemente existe a conotação positiva que Bakhtin constatou nas manifestações populares de outros tempos, afinal a exuberância sexual de D. Pedro é a fonte de onde jorram as sementes que gerariam vida, por gerações e gerações, de modo a constituir a gênese simbólica da nação (Pucci Jr., 2003b). Todavia, algumas observações devem ser feitas. A primeira delas é que, se é tão consistente o anacronismo em relação à época em que se passa história, conforme verificado acima, ele não se articula da mesma forma no aspecto ideológico. Em outras palavras, projeta-se sobre o início do século XIX não a perspectiva ideológica dos dias atuais, como em Carlota Joaquina (Pucci Jr., 2000, p. 135-138), mas a do período em que vicejou a pornochanchada, isto é, os anos mais terríveis da ditadura militar. Duplo anacronismo, portanto, em que os personagens e situações não são constituídos à luz da época em que foi realizada a minissérie, mas de trinta anos antes.

Examine-se em detalhes essa configuração. A virilidade de D. Pedro, mote de dezenas de cenas ao longo dos capítulos, chega ao nível da exaltação, quase sempre em detrimento das figuras femininas. O que significa a maioria das mulheres para esse irreprimível 
pai da pátria, senão a multidão de mães em quem deposita o futuro? "E haverá melhor coisa a fazer com elas?" - diz ele diversas vezes, em formulações variadas. É com esse espírito que demonstra atração por damas da corte, esposas de negociantes e escravas, muitas escravas, que lhe propiciam uma prole de infinitos matizes de cor. As mais importantes personagens femininas não escapam desse quadro. Leopoldina é absolutamente passiva, tanto que toma conhecimento das aventuras sexuais do marido e jamais faz qualquer reclamação mais séria. "Sou uma mulher feliz, Pedro!", declara, mesmo tendo que conviver com as visitas que o marido faz aos leitos alheios. Domitila é atrevida, agressiva e dominadora, contudo o que pretende senão viver às custas das benesses do imperador? É uma amante à antiga, que, ao receber uma casa de presente, diz ser aquilo tudo com que sonhou na vida. Amélia, a segunda imperatriz, gosta de mandar, não só nos escravos e lacaios, como também no imperador. No entanto, nada consegue com ele. Sua fragilidade é ostentada, por exemplo, na cena em que D. Pedro coloca-a para fazer musculação: sob vestes brancas e delicadas, é incapaz de executar o menor exercício físico, em contraposição à pujante força muscular do marido. Carlota Joaquina é provavelmente a figura mais masculinizada entre as mulheres. Luta pelo que deseja, não mede conseqüências, ataca D. João VI inclusive fisicamente. Quando Miguel finalmente dá um golpe de Estado em Portugal e chega ao poder, o comentário de D. Pedro é o de que o irmão chegou a isso através das "bolas de Carlota". Entretanto, também ela é uma mulher como as outras, tanto que, pouco antes da morte de D. João VI, joga-lhe na cara: "Pensas que porque estou ao sol, não estou encarcerada, presa neste corpo de mulher, sexo amaldiçoado, a quem tudo negam?'. Em verdade, o poder lhe é negado, por isso é obrigada a agir por artimanhas e a entregar o poder ao filho dileto.

É inegável que tais configurações femininas podem, em linhas gerais, ser atribuídas ao patriarcado do início do século XIX. No entanto, à luz do que foi dito acerca do pós-modernismo da minissérie, ou seja, que ele se constitui basicamente em termos de paródia lúdica e de anacronismos, é lícito indagar por que em 
relação às figuras femininas a paródia e as referências não se fizeram em função da posição da mulher na época em que se produziu a minissérie. A concepção acerca da mulher é muito menos a da severa mulher do século XIX que a das pornochanchadas realizadas em torno do sesquicentenário da Independência, nas quais, com honrosas exceções, também as mulheres eram passivas ou espertalhonas e, de todas as cores e classes sociais imagináveis, "lebres a serem abatidas". ${ }^{4}$

A mesma formulação redutora se apresenta em relação a outras minorias sociais, ou seja, àqueles que se encontram nas margens da sociedade, na acepção de Linda Hutcheon (1991, p. 84103). Pode-se mencionar uma simultânea referência depreciativa aos indígenas e ao sexo feminino: "Há tantas mulheres no Brasil. E as índias já vêm nuas". Embora não se veja um único índio no decorrer da minissérie, ao contrário do que acontecia no filme de Carla Camurati, no qual surgem em grupos, as imprecações de Carlota dão uma idéia de sua escala de valores: "Que gente horrorosa. O melhor é saber que não vou ter mais que ver nenhum desses bugres. $\mathrm{E}$, quando chegar a Lisboa, vou pensar que estava cega, tantos foram os anos que estive no escuro, tantos foram os negros que vi neste inferno!". Curiosamente, nessa cena, a da partida de Carlota do Brasil, ela fala não a índios, negros ou mestiços, mas a um grupo de brancos bem vestidos, o que não impede que receba sonora vaia. Nesse ponto, a minissérie recorda intensamente Independência ou Morte, em que o povo brasileiro se resumia a uns poucos brancos que ouviam os discursos de D. Pedro (Tarcisio Meira) ou, no máximo, se condensava nos amigos do imperador, sempre brancos, que comiam e bebiam com ele na taberna por ele freqüentada. ${ }^{5}$

Os negros são quase sempre submissos ou idiotizados. De um lado, servem à família real de forma inexpressiva e de cabeça

4. Quando as Mulheres Paqueram (Victor di Mello, 1972) é uma das pornochanchadas em que não se denigre a figura feminina, ao menos nos termos entāo habituais.

5. O que provocou o incrédulo espanto de Jean-Claude Bernardet (1978, p. 209). A suspeita definição de povo em Independência ou Morte foi analisada em Pucci Jr., 2000, p. 131-134. 
baixa; de outro, ficam com ar estupidificado à porta do quarto de $\mathrm{D}$. Pedro e Amélia a escutar a fingida briga do casal. Verdade é que D. Pedro se esparrama em elogios à beleza das negras, mas nesse caso, como em relação às brancas, trata-se apenas de colocá-las em função de seu desejo sexual.

O grosseiro desrespeito atinge até os gordos, especialmente Leopoldina, com diversas cenas em que se debocha de seu peso. Menosprezada, a princípio, por D. Pedro, que pretendia uma esposa mais bela, Leopoldina sofre chacotas generalizadas, por exemplo, "Já emprenhou a bolota?" (D. João VI a D. Pedro) e as referências ao seu tamanho na cena em que o imperador conversa com a costureira acerca de problemas com os vestidos de Leopoldina:

Costureira: O problema é que o tecido era pequeno.

D. Pedro: Como pequeno?!

Costureira: Não se pode esquecer que agora ela vive grávida.

D. Pedro: Mas levei isso em conta! Vem cá. Informei-me. Para uma mulher normal precisa-se de cinco metros de tecido. Por via das dúvidas, comprei peças três vezes maiores [...]. Não é possível que tenha aumentado ainda mais do que na última gravidez! Nem ao quarto mês chegou ainda! [a costureira faz uma expressão de assombro].

Esse ridículo é pouco diante do que sofre a figura mais espezinhada de toda a minissérie: Miguel, o irmão de D. Pedro (e não D. João VI, que aos poucos vai adquirindo feições simpáticas e dignas). A motivação para tanta zombaria é o desejo homossexual pelo irmão. No armário durante a maior parte do tempo, Miguel revela seu desejo apenas quando está sozinho. De qualquer modo, sua figura antipática, covarde, traiçoeira e maléfica é constantemente associada à homossexualidade. Isso se explicita quando Gomes, já então chamado de Chalaça, bate os olhos em Miguel e não hesita em interpelá-lo: "Um veado como tu!", com irreprimível ar de nojo. A cada momento em que seus trejeitos se manifestam, o caráter desagradável o acompanha: caber-lhe-ia perfeitamente o rótulo de "bicha histérica" em razão das explosões nervosas que D. Pedro é incapaz 
de entender, pois nem imagina que é a paixão do irmão por ele próprio que motiva imprecações contra as mulheres, as amantes e as esposas de D. Pedro.

Miguel é o grande vilão da história. Manda duas vezes matar D. Pedro; em outros dois momentos, toma a iniciativa de tentar provocar-lhe a morte (corta o arreio do cavalo de $\mathrm{D}$. Pedro e retira a proteção do florete do adversário de esgrima do irmão). Esse personagem aristocrático, com tudo o que a palavra carrega de negativo em contraposição à mundanidade feliz de D. Pedro, é falso, reprimido sexualmente, cruel e chega a ponto de tentar matar Amélia colocando veneno no leite. De volta a Portugal, prende D. Pedro e o submete à tortura a fim de derrubar a resistência do irmão ao desejo incestuoso e homossexual. Por fim, tudo perdido e jogado na prisão, é pela última vez ridicularizado, mais uma vez por Chalaça, que lhe joga na cara que, por ser tão covarde, é incapaz até de se suicidar.

Não poderia haver um retrato mais pejorativo de um personagem homossexual, o que recorda, é claro, as vilipendiosas caçoadas a que tais personagens eram submetidos em diversas pornochanchadas, mais uma evidência de que é a moral dos anos setenta que nutre a narração de $O$ Quinto dos Infernos. ${ }^{6}$

Realça-se o caráter dúbio da minissérie, em comparação com Carlota Joaquina e outros filmes pós-modernos brasileiros, quando se pensa que o pós-modernismo consiste não só num estilo que paradoxalmente funde cultura de massa e modernismo, mas também numa certa visão do significado da arte em relação à ideologia. Sem implodir a cultura dominante, o pós-modernismo busca desafiála a partir de seu interior (Hutcheon, 1991, p. 16). Em O Quinto dos Infernos inexiste a ironia lúdica com que são tratados os elementos que circulam na cultura de massa: os preconceitos de D. Pedro, Chalaça e demais personagens devem ser entendidos literalmente;

6. Um exemplo menos cristalino, nem por isso mais respeitoso: em Quando as Mulheres querem Provas (Cláudio MacDowell, 1975), vários personagens passam boa parte do tempo a caçoar do protagonista (Carlo Mossy) e de outro homem, considerados homossexuais; na verdade, trata-se de um mal-entendido, pois ambos são apenas amigos. Segundo a perspectiva do filme, tudo indica que, caso fossem mesmo homossexuais, justificar-se-iam as chacotas. Hoje é improvável que o cinema nacional produza enredos nessa linha. 
daí não existir espaço para a crítica da cultura em foco. ${ }^{7}$ No longa de Carla Camurati, ao contrário, nunca se sustentam os preconceitos acima descritos, pois, enunciados por Carlota, tendem a ser desmoralizados pela própria antipatia da personagem. Além disso, chegase à afirmação do oposto ao preconceito quando um papel honrado e de destaque é entregue a um ator negro: Fernando Carneiro Leão (Norton Nascimento), último amante de Carlota. Sua esposa, negra também, é quem demonstra mais dignidade diante de Carlota, num gesto que resulta no revoltante assassinato da súdita atrevida. Entre outros filmes na mesma linha, pode-se citar Caramuru - a Invenção do Brasil (Guel Arraes, 2001), absolutamente pós-moderno não apenas no que concerne à paródia lúdica com função distanciadora, como também no tratamento da etnia indígena e das mulheres.

É possível que a combinação paradoxal do pós-modernismo (ousadia modernista em conjunto com a alta comunicabilidade da cultura de massa) ainda não se tenha conjugado na TV brasileira de forma completa, isto é, com a propagação de valores que a têm acompanhado não só no cinema como também na literatura, fotografia e demais artes. $\mathrm{O}$ resultado é o pós-modernismo de fachada, equivalente a edifícios de tipologia modernista aos quais se acrescenta algum detalhe da nova vulgata: uma abóbada de vidro, uma clarabóia piramidal, um tímpano desproporcionado aplicado à cobertura. Interpretação superficial do pós-modernismo, perde de vista o debate fomentado pelo pós-moderno e seus frutos no plano criativo (Portoghesi, 2002, p. xiii).

É plausível imaginar o que resultaria de tal combinação com um público que com freqüência alcança dezenas de milhões de espectadores a cada noite. Mas talvez o entrave esteja precisamente nesse índice, comparável em algum sentido aos que atingiam as pornochanchadas.

7. Linda Hutcheon (2000) desenvolveu seu conceito de ironia, elemento básico da paródia, especialmente nas p. 72-88, em que faz a enumeraçāo das diferentes funções da ironia, entre as quais, está a função lúdica. 


\section{Bibliografia}

BAKHTIN, Mikhail. 2002. A cultura popular na Idade Média e no Renascimento. 5. ed. São Paulo: Annablume/Hucitec.

BERNARDET, Jean-Claude. 1978. "Nota sobre Independência ou Morte". In: Trajetória crítica. São Paulo: Polis, pp. 208-209.

GATTI, José. 2000. "Lusofonia no Cinema Brasileiro: notas sobre a presença de línguas no cinema". In: Estudos de cinema: Socine II e III. pp. 86-97. São Paulo: Annablume.

HUTCHEON, Linda. 1989. The politics of Postmodernism. Londres e Nova York: Routledge.

1991. Poética do Pós-Modernismo. Rio de Janeiro: Imago. 2000. Teoria e política da ironia. Belo Horizonte: UFMG.

HUYSSEN, Andreas. 1986. After the great divide: Modernism, mass culture and Postmodernism. Londres: Macmillan Press.

MELLO, Evaldo Cabral. 2002. Folha de São Paulo. 13 jan, p. A-9. Entrevista.

NASCIMENTO, Geraldo C. 2001. "O Tempo Mnésico da Enunciação e o Tempo Crônico do Enunciado em Carlota Joaquina". Significação - Revista Brasileira de Semiótica, São Paulo, n.. 16, nov., p. 45-63.

PORTOGHESI, Paolo. 2002. Depois da Arquitetura Moderna. São Paulo: Martins Fontes.

PUCCI JR., Renato Luiz. 2000. "Carlota Joaquina: as raízes da Nação". Fronteiras - Revista Catarinense de História. Florianópolis, n. ${ }^{\circ}$ 8, dez, p. 125-145.

2003a. Cinema Brasileiro Pós-Moderno: estilo parado$x a l$, em direção a uma Poética. São Paulo: 312 p. Tese de doutorado em Ciências da Comunicação - Escola de Comunicações e Artes, Universidade de São Paulo.

2003b. "O Nascimento de uma Certa Nação". In: Corpo e Mídia. São Paulo: UNIP (no prelo).

VAINFAS, Ronaldo. 2001. "Carlota: caricaturas da História". In: A História vai ao Cinema: vinte filmes brasileiros comentados por 
historiadores. Org.: Mariza de Carvalho Soares e Jorge Ferreira. Rio de Janeiro: Record.

WHITE, Hayden. 1994. "Teoria Literária e escrita da História". Estudos Históricos. Rio de Janeiro, vol. 7, n. ${ }^{\circ} 13$, pp. 21-48. 1998. "O Evento Modernista". Lugar Comum, n. 5-6, maidez, pp. 191-219. 